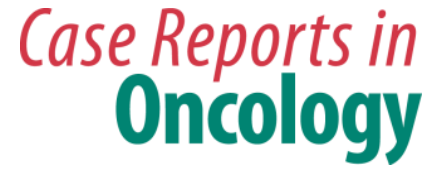

Case Rep Oncol 2018;11:467-475

DOI: 10.1159/000490636

Published online: July 13, 2018

c) 2018 The Author(s)

Published by S. Karger AG, Basel

www.karger.com/cro

This article is licensed under the Creative Commons Attribution-NonCommercial 4.0 International License (CC BY-NC) (http://www.karger.com/Services/OpenAccessLicense). Usage and distribution for commercial purposes requires written permission.

\title{
Favorable Response to Treatment with Avelumab in an HIV-Positive Patient with Advanced Merkel Cell Carcinoma Previously Refractory to Chemotherapy
}

\author{
Mohammed U. Al Homsi ${ }^{a} \quad$ Mai Mostafa $^{a} \quad K^{2}$ aled Fahim ${ }^{b}$ \\ aNational Center for Cancer Care and Research, Doha, Qatar; ${ }^{b}$ Merck Serono Middle East \\ FZ-LLC, Dubai, UAE
}

\section{Keywords}

Merkel cell carcinoma $\cdot$ Avelumab $\cdot$ Immunotherapy

\begin{abstract}
Avelumab is indicated for the management of Merkel cell carcinoma, a rare and aggressive neuroendocrine skin cancer. Its regulatory approval followed the positive outcome of a Phase 2 trial on 88 patients with stage IV disease, which excluded patients with immunodeficiency due to HIV, a risk factor for this cancer type. We report a positive and sustained response to avelumab in an HIV-positive patient with stage IV Merkel cell carcinoma refractory to previous chemotherapy (cisplatin/etoposide) and radiotherapy. Five cycles of avelumab $10 \mathrm{mg} / \mathrm{m}^{2} \mathrm{re}-$ sulted in the resolution of tumor activity visualized using PET-CT scanning in all affected lymph nodes. The only major side effect associated with avelumab was thyroiditis and mild hypothyroidism, a known adverse effect of this treatment, which was well controlled by L-thyroxine treatment. Treatment is ongoing and the positive response has been sustained during 5 further cycles of treatment up to date. This apparently durable response is consistent with the earlier
\end{abstract}




\section{Case Reports in Oncology}

Case Rep Oncol 2018;11:467-475

DOI: $10.1159 / 000490636$ (C) 2018 The Author(s).
www.karger.com/cro

(C) 2018 The Author(s). Published by S. Karger AG, Basel

Al Homsi et al.: Avelumab in Advanced Merkel Cell Carcinoma

clinical trial experience with avelumab, but seen here in a patient with HIV-associated immunodeficiency as a predisposing factor (an exclusion criterion from the previous trial). Further clinical trials with avelumab in a broader patient population with Merkel cell carcinoma are warranted.

(C) 2018 The Author(s)

Published by S. Karger AG, Basel

\section{Introduction}

Merkel cell carcinoma is a rare form of skin cancer arising in mechanoreceptors situated at the junction between the dermis and the epidermis. It accounts for $<1 \%$ of all skin cancer cases in Europe, and about 1,500 cases are diagnosed each year in the USA [1,2]. An increasing prevalence of Merkel cell carcinoma has been attributed to several factors, including better diagnosis (the disease has only been recognized for about 45 years), increased life expectancy $(>90 \%$ of all cases arise in people aged $>50$ years), and greater associated exposure to certain risk factors, including increased exposure to sunlight and longer survival of people with compromised immune systems (e.g., due to posttransplant immunosuppression or HIV) [2]. The long-term prognosis associated with Merkel cell cancer is poor: 5-year survival rates have been estimated as $50 \%$ for stage IIIA disease, $45 \%$ for stage IIIB disease, and only $20 \%$ for stage IV disease [3]. Mortality due to Merkel cell carcinoma appears to be higher than that associated with malignant melanoma, at least for earlier forms of metastatic disease [1] (e.g., the 5-year survival rate with malignant melanoma has been estimated to be $78 \%$ [4]).

"Immune checkpoints" regulate the balance between stimulation and suppression of the immune system, to prevent autoimmune damage during immune activation [5, 6]. Monoclonal antibodies designed to inhibit the action of immune checkpoints that act as a brake on the immune system, such as receptor PD-1, have the potential to optimize the immune response to a tumor $[4,5]$. This action has been described as "moving the balance from a pro-tumor to an antitumor microenvironment" [5].

Avelumab is a PD-1 inhibitor that gained accelerated regulatory approval [7]. This was based on the successful outcome of the JAVELIN Phase 2 trial on 88 adult patients with stage IV Merkel cell carcinoma refractory to prior chemotherapy [8]. The overall response rate in this trial was 33\%, including $11 \%$ who had complete responses. Patients with HIV as a predisposing factor were excluded from the JAVELIN trial; however, and it is of interest to study the actions of avelumab in such patients. We present our experience with the use of avelumab in the management of metastatic Merkel cell carcinoma that recurred despite previous chemotherapy and radiotherapy.

\section{Case Presentation}

\section{Initial Clinical Presentation}

A chronological account of the management of this patient is given below. Table 1 contains a simplified timeline of key events for reference. The patient was a Black male from South Africa, aged 39 years, who had been working in Doha, Qatar, for 7-8 years without any known 


\section{Case Reports in Oncology}

Case Rep Oncol 2018;11:467-475

DOI: $10.1159 / 000490636$

(C) 2018 The Author(s). Published by S. Karger AG, Basel www.karger.com/cro

Al Homsi et al.: Avelumab in Advanced Merkel Cell Carcinoma

chronic illnesses at the time of initial presentation to a private hospital (March 2016). He complained of a painless swelling on the right lower thigh, which had slowly enlarged in size over the previous 3 months. There was no limitation of movement and no history of trauma. Histopathology of the excised skin lesion revealed a poorly differentiated tumor; differential diagnosis suggested possibility of Merkel cell carcinoma, non-Hodgkin lymphoma, squamous cell carcinoma, cutaneous alveolar rhabdomyosarcoma, or melanoma.

A referral to a general hospital for definitive diagnosis was made, but the patient did not keep the appointment and was lost to follow-up. However, in June 2016, he presented again to a hospital with a rapidly enlarging swelling in the right inguinal area. A right inguinal lymph node biopsy in September 2016 showed a poorly differentiated tumor, considered to be a malignant lymph node metastasis or a lymphoma. Referral to the Dermatology Department of the same general hospital was done in October 2016. Healed surgical scars from the initial excision of the tumor and the lymph node biopsy were evident, and there were no palpable lymph nodes in the left inguinal area, the neck, or either axilla. The patient was referred to the Medical Oncology Department for imaging the next day.

PET-CT findings, a review of histopathological specimens, histochemical analysis, and results of blood tests are summarized in Table 2. Online supplementary Figure S1 (for all online suppl. material, see www.karger.com/doi/10.1159/000490636) shows baseline PET-CT images used for staging (see also the section on avelumab treatment below). Briefly, the results were consistent with a neuroendocrine tumor apparently contained within the lymph nodes (a biopsy of the lymph nodes from the axillae did not find evidence of tumor cells despite FDG uptake on PET-CT). These findings, plus positivity for CK-20 and negativity for CK-7, TTF-1, and S-100 on immunohistochemical analysis were consistent with a diagnosis of Merkel cell carcinoma [9]. The blood tests confirmed that the patient was HIV positive and carrying several viral infections commonly associated with a compromised immune system. The patient was referred to the infectious disease clinic and was started on standard HIV-antiviral medications. The patient's response to the treatment was excellent showing a reduction in the viral load.

\section{Prior Chemotherapy and Radiotherapy}

Four cycles of cisplatin $\left(25 \mathrm{mg} / \mathrm{m}^{2}\right)$ and etoposide $\left(100 \mathrm{mg} / \mathrm{m}^{2}\right)$ were given (November 20,2016 , to January 30,2017 ), with each drug given on days 1,2 , and 3 of a 21 -day cycle. PETCT imaging the following month showed an increasing size and uptake in the right external iliac lymph node (currently $4 \times 3.3 \mathrm{~cm}$, with $\mathrm{SUV}_{\max }$ increased to 20.4 from a previous value of 7.7) and increasing size and uptake in the right inguinal metastatic lymph node. Previously observed left inguinal/iliac and bilateral axillary FDG-avid lymphadenopathy had resolved (note that the prior axillary biopsy was negative, as described above).

Local radiotherapy (March-April 2017; rapid arc technique) was given to the pelvic paraaortic right inguinal regions and produced a mixed response (see Fig. 1, online suppl. Table S1, and Fig. S2 for further details of dosage and direction of radiation). There was disease progression (new upper retroperitoneal mediastinal and left supraclavicular lymph node metastases) accompanied by a favorable response in the right external iliac and right inguinal metastatic lymph nodes. A grade III skin reaction in the irradiated area resolved with supportive care. 


\section{Case Reports in Oncology}

Case Rep Oncol 2018;11:467-475

DOI: $10.1159 / 000490636$

(C) 2018 The Author(s). Published by S. Karger AG, Basel www.karger.com/cro

Al Homsi et al.: Avelumab in Advanced Merkel Cell Carcinoma

\section{Effects of Avelumab}

Avelumab was administered as 5 doses of $10 \mathrm{mg} / \mathrm{kg}$ every 2 weeks (June 15 to September 16, 2017; total dose 1,000 mg). PET-CT 2 days after the final dose showed a favorable treatment response, with resolution of previously seen lymph nodal activities in the right external iliac/right inguinal, upper retroperitoneal, mediastinal, and left supraclavicular areas (Fig. 2). An observation of new intense uptake in a left axillary lymph node was not considered progression according to immune response assessment criteria (Fig. 3). Multiple lymph nodes showing fatty hila were seen on an ultrasound scan of the right axilla at this time. Few of these showed a prominent hypodense cortex, and the largest measured $9 \times 5 \mathrm{~mm}$; these will be monitored during continued follow-up.

The principal toxicity experienced by this patient was thyroiditis, which was evident on a PET-CT scan, accompanied by mild hypothyroidism (see online suppl. Fig. S3 for the evolution of thyroid function tests over time during treatment with avelumab). The patient was managed successfully with L-thyroxine. An observation of concomitant neutropenia (see online suppl. Fig. S4) was unlikely to be related to avelumab, as this emerged before avelumab was started. Appropriate management of the patient's HIV saw the HIV load fall from $>110,000$ copies/mL at presentation to $<2,000$ copies/mL by March 2017. Liver function tests, and blood pressures remained within normal limits during the treatment with avelumab (online suppl. Figs. S5 and S6). Overall, the patient tolerated treatment with avelumab well, without complaints, and maintained an active working life and usual daily activities throughout treatment. Treatment with avelumab is continuing.

\section{Discussion}

Avelumab was considered for this patient, as it is approved for this indication, supported as a management option for Merkel cell carcinoma by clinical guidelines [9] and because clinical experience with immune checkpoint inhibitors may provide durable therapeutic responses $[1,5,9]$. Previous management with cytotoxic chemotherapy and radiotherapy had produced a mixed response, with some local resolution of tumor activity visualized on PETCT, but also some progression of disease activity at distant sites.

Avelumab, in contrast, induced rapid resolution of tumor activity on PET-CT. In addition, treatment with avelumab was well tolerated. Activation of autoimmune disease, including thyroiditis, is a recognized side effect of this treatment [10]. The prescribing information for avelumab [10] permits continued treatment in patients who develop thyroid dysfunction as long as this is not severe (grade 3) or life threatening (grade 4). Accordingly, continued treatment with avelumab was appropriate in this case as his mild hypothyroidism was managed adequately with hormone replacement therapy.

The responses described above were obtained following 5 cycles of avelumab. Up to date, this patient has received 10 cycles of avelumab, with maintained response to treatment. Durable tumor responses to PD-1 inhibition have been described previously, including with avelumab: a recent publication from the JAVELIN cohort showed that $74 \%$ of the objective responses lasted for $>1$ year, with $72 \%$ of the responses maintained at the time of analysis, so that the median duration of response could not be established [11]. Moreover, progressionfree survival was $30 \%$, and overall survival was $52 \%$, each at 1 year. 
Our experience is consistent with this clinical trial experience, and adds useful information in a patient with HIV-associated immunodeficiency, which was not addressed in JAVELIN. Further clinical evaluation of avelumab is warranted in a broader population of patients with Merkel cell carcinoma.

\section{Acknowledgements}

Dr. Mike Gwilt (a medical writer), GT Communications, funded by Merck, provided editorial assistance to the authors.

\section{Statement of Ethics}

The authors are grateful to our patient, who provided informed consent for the publication of this case report.

\section{Disclosure Statement}

K.F. is an employee of Merck. M.U.A.H. and M.M. have no conflicts of interest to disclose.

\section{References}

1 Schadendorf D, Lebbé C, Zur Hausen A, Avril MF, Hariharan S, Bharmal M, et al. Merkel cell carcinoma: Epidemiology, prognosis, therapy and unmet medical needs. Eur J Cancer. 2017 Jan;71:53-69.

2 American Cancer Society. Key statistics for Merkel cell carcinoma. Available at https://www.cancer.org/cancer/merkel-cell-skin-cancer/about/key-statistics.html (accessed May 2018).

3 American Cancer Society. Survival Rates for Merkel Cell Carcinoma, by Stage. Available at https://www.cancer.org/cancer/merkel-cell-skin-cancer/detection-diagnosis-staging/survival-rates.html (accessed May 2018).

4 American Cancer Society. Survival Rates for Melanoma Skin Cancer, by Stage. Available at https://www.cancer.org/cancer/melanoma-skin-cancer/detection-diagnosis-staging/survival-rates-formelanoma-skin-cancer-by-stage.html (accessed May 2018).

5 Alsaab HO, Sau S, Alzhrani R, Tatiparti K, Bhise K, Kashaw SK, et al. PD-1 and PD-L1 Checkpoint signaling inhibition for cancer immunotherapy: mechanism, combinations, and clinical outcome. Front Pharmacol. 2017 Aug;8:561.

6 Iwai Y, Hamanishi J, Chamoto K, Honjo T. Cancer immunotherapies targeting the PD-1 signaling pathway. J Biomed Sci. 2017 Apr;24(1):26.

7 Kim ES. Avelumab: First Global Approval. Drugs. 2017 May;77(8):929-37.

8 Kaufman HL, Russell J, Hamid O, Bhatia S, Terheyden P, D’Angelo SP, et al. Avelumab in patients with chemotherapy-refractory metastatic Merkel cell carcinoma: a multicentre, single-group, open-label, phase 2 trial. Lancet Oncol. 2016 Oct;17(10):1374-85.

9 National Comprehensive Cancer Network. NCCN Guidelines Version 1.2018. Merkel cell carcinoma. Available at http:www.nccn.org (accessed May 2018).

10 US Prescribing Information for Bavencio® (avelumab): Available at https://www.accessdata.fda.gov/drugsatfda_docs/label/2017/761049s000lbl.pdf (accessed May 2018).

11 Kaufman HL, Russell JS, Hamid O, Bhatia S, Terheyden P, D'Angelo SP, et al. Updated efficacy of avelumab in patients with previously treated metastatic Merkel cell carcinoma after $\geq 1$ year of follow-up: JAVELIN Merkel 200, a phase 2 clinical trial. J Immunother Cancer. 2018 Jan;6(1):7. 


\section{Case Reports in Oncology}

Case Rep Oncol 2018;11:467-475

DOI: $10.1159 / 000490636$

(C) 2018 The Author(s). Published by S. Karger AG, Basel www.karger.com/cro

Al Homsi et al.: Avelumab in Advanced Merkel Cell Carcinoma
Before treatment

a) Increased tumor dimension following cytotoxic chemotherapy

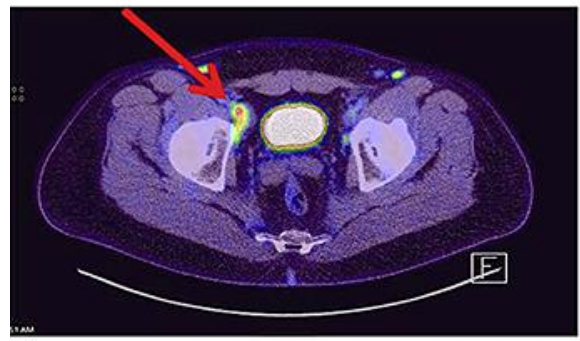

b) Favorable local response to radiotherapy
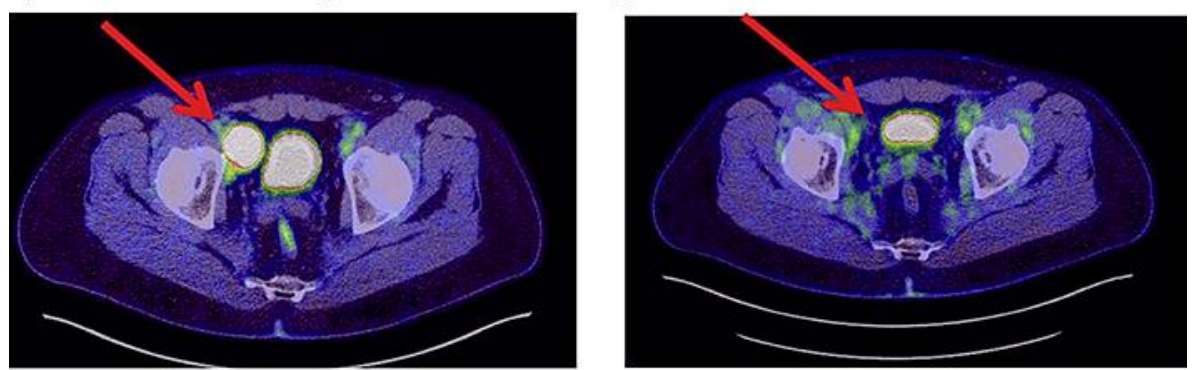

c) Distant disease progression after radiotherapy

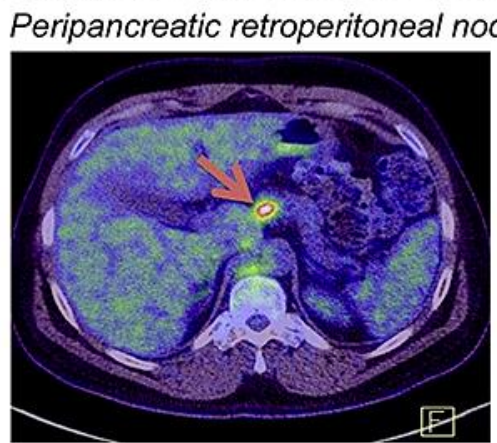

Lower Mediastinal para-aortic node
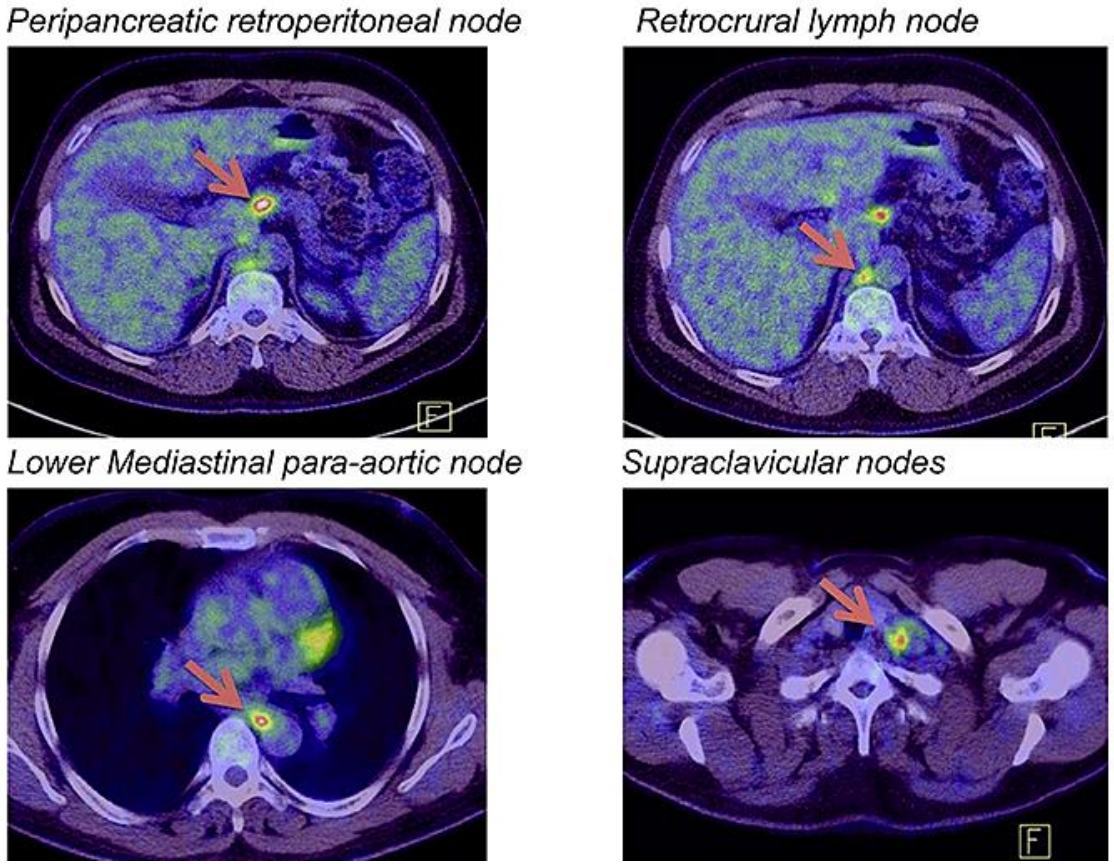

Supraclavicular nodes

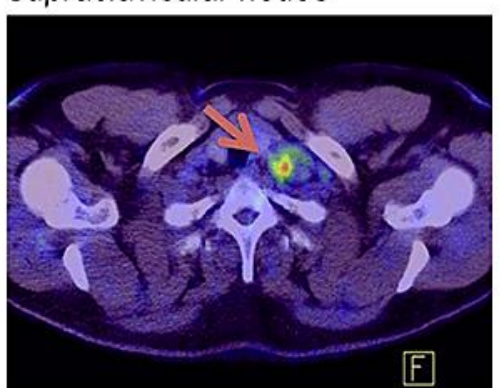

Fig. 1. Mixed response of Merkel cell carcinoma to chemotherapy and radiotherapy. 


\section{Case Reports in Oncology}

Case Rep Oncol 2018;11:467-475

DOI: $10.1159 / 000490636$

Al Homsi et al.: Avelumab in Advanced Merkel Cell Carcinoma
Before avelumab

a) Resolution of retroperitoneal node

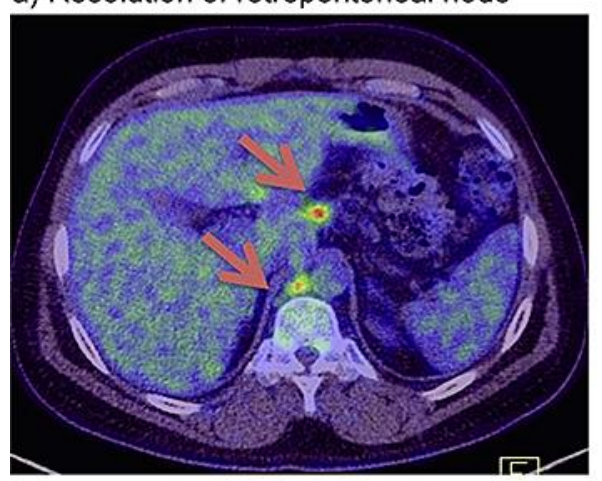

b) Resolution of supraclavicular lymph nodes

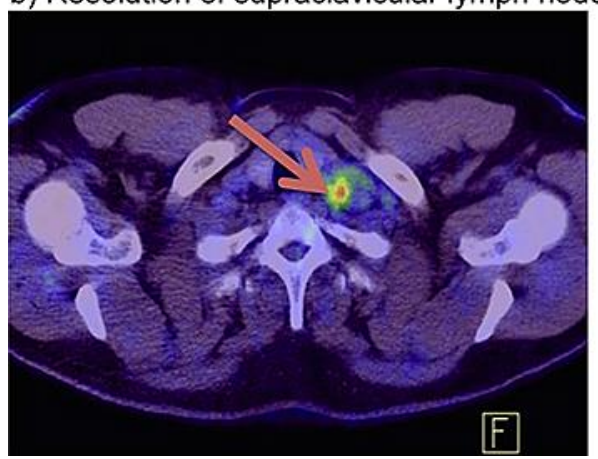

After avelumab
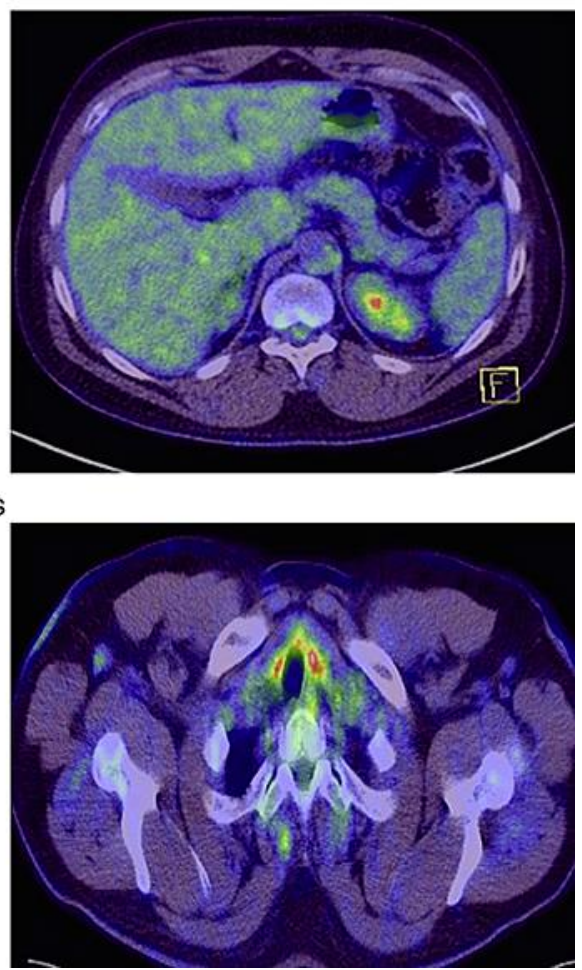

Fig. 2. PET-CT scans showing examples of Merkel cell tumor responses to 5 cycles of avelumab.

a) Increased thyroid uptake (thyroiditis)

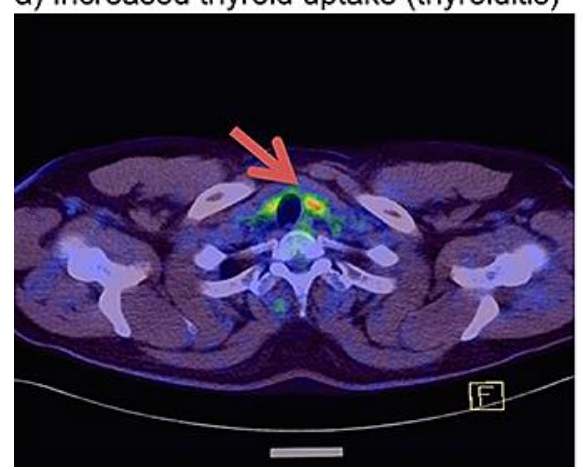

b) New uptake in left axillary lymph node ${ }^{a}$

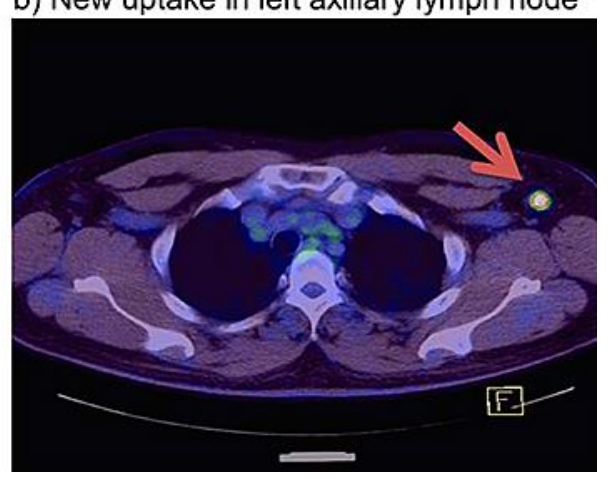

Fig. 3. Other PET-CT findings with avelumab. a Not considered progression according to immune response assessment criteria (see text). 
Table 1. Summary of the timeline of patient management

\begin{tabular}{ll}
\hline Date & Event \\
\hline Jan-Mar 2016 & $\begin{array}{l}\text { Patient presented to a private hospital with a swelling on his thigh } \\
\text { Skin lesion was excised, patient was referred to a general hospital and lost to } \\
\text { follow-up } \\
\text { Histopathology includes Merkel cell carcinoma as possible diagnosis }\end{array}$ \\
\hline Jun-Sept 2016 & $\begin{array}{l}\text { Patient re-presented to a hospital } \\
\text { Histopathology of right inguinal lymph node biopsy showed poorly differentiated } \\
\text { neuroendocrine tumor }\end{array}$ \\
\hline Oct 2016 & $\begin{array}{l}\text { PET-CT showed enhanced FDG uptake into multiple lymph nodes without signs of } \\
\text { organ or bone involvement } \\
\text { Immunohistochemistry consistent with diagnosis of Merkel cell carcinoma } \\
\text { HIV-positive status discovered }\end{array}$ \\
\hline Nov 2016-Jan 2017 & Chemotherapy with cisplatin/etoposide was followed by disease progression \\
\hline Jul 2017 & $\begin{array}{l}\text { Mixed results following radiotherapy (tumor shrinkage at some sites together with } \\
\text { new distant metastases) }\end{array}$ \\
\hline Jun-Sept 2017 & $\begin{array}{l}\text { Five cycles of avelumab (10 mg/m²) } \\
\text { Favorable tumor response with resolution of lymph node activities } \\
\text { Emergence of thyroiditis/mild hypothyroidism as a side effect of therapy }\end{array}$ \\
\hline After Sep 2017 & $\begin{array}{l}\text { Treatment ongoing (5 further cycles of avelumab) } \\
\text { Response has been maintained, and patient tolerates treatment well }\end{array}$ \\
\hline
\end{tabular}


Table 2. Clinical tumor characteristics before chemotherapy

\begin{tabular}{ll}
\hline Analysis & Key findings \\
\hline PET-CT & $\begin{array}{l}\text { FDG-avid right inguinal obturator and iliac lymph nodes } \\
\text { Intense uptake in the left inguinal/iliac lymph nodes } \\
\text { Uptake in bilateral axillary lymph nodes (reminiscent of lymphoma or lymphadenitis) } \\
\text { No sign of organ or bone involvement }\end{array}$ \\
\hline Histopathology & $\begin{array}{l}\text { Fragments of fibro-adipose tissue } \\
\text { Lymph node tissue totally replaced by a neuroendocrine tumor, characterized by } \\
\text { trabeculae and nests of medium-sized tumor cells with a high N/C ratio }\end{array}$ \\
& $\begin{array}{l}\text { Hyperchromatic nuclei with powdery chromatin and conspicuous nucleoli } \\
\text { Numerous mitotic figures }\end{array}$ \\
\hline Immuno- & $\begin{array}{l}\text { Strong positive for CK AE1/AE3, synaptophysin, chromogranin, CD56, and CK 20 } \\
\text { histochemistry }\end{array}$ \\
\hline Blood work & $\begin{array}{l}\text { Positive for Treponema pallidium antibodies, Treponema pallidium antibody } \\
\text { confirmation, cytomegalovirus antibody IgG } \\
\text { Negative for cytomegalovirus antibody IgM, toxoplasma antibody IgG, toxoplasma } \\
\text { antibody IgM, hepatitis B surface antigen }\end{array}$ \\
HIV PCR = 110,672 copies/mL
\end{tabular}

